\title{
Barriers to Entering Higher Education: Rural Students' Perspective
}

\author{
Anna Hughes \\ Red River College, Canada
}

\begin{abstract}
A disparity in access to higher education exists between rural and urban regions of the world. Equal access to higher education for students from rural areas is a priority for government leaders in Kyrgyzstan and Tajikistan where this study took place. The study addressed the problem of enrollment of students from rural areas at branches of the International Mountainous University (IMU, pseudonym) located in rural regions of Kyrgyzstan and Tajikistan. The purpose of this qualitative case study was to investigate the experiences and perceptions of 10 IMU students about gaining access to higher education. Informed by the theory of habitus, the research questions focused on perceptions of $(a)$ the experience of gaining access and (b) sacrifices related to gaining access to higher education. Four themes emerged: (a) academic barriers, (b) information and communication barriers, (c) support, and (d) material and nonmaterial sacrifices. The study provides a better understanding of access challenges experienced by rural Kyrgyz and Tajik residents, allowing institutions and governments to improve current outreach practices and potentially create long-term strategies for rural development.
\end{abstract}

\section{Introduction}

A disparity in access to higher education exists between rural and urban regions of the world. This disparity is aligned with a general trend of vulnerability and lack of access to basic amenities for rural residents globally. According to [19], people living in rural areas, regardless of their location and country of origin, have limited access to health, education, and social services and are more vulnerable than those living in urban areas. Equal access to higher education, particularly for residents of rural areas, is a top priority for all developing countries, including Kyrgyzstan and Tajikistan. The purpose of this study was to investigate perceptions and experiences of students from rural areas of Kyrgyzstan and Tajikistan who study at branches of the International Mountainous University (IMU, pseudonym) with campuses in rural Kyrgyzstan and Tajikistan. An understanding of the experiences and perceptions of these students regarding access to higher education, as well as identification of any barriers they may have encountered, may inform the development of better institutional practices for recruiting and admitting rural students in the region.

\section{Conceptual framework}

Bourdieu's [2] theory of habitus informed the study. According to Bourdieu, people's educational paths and access options are predetermined and constrained by their habitus, or a set of dispositions that include such individual circumstances as urban or rural origin, family background, and financial status. Habitus refers to the relative position of an individual within the social world [3]. Bourdieu and Wacquant [5] explained the concept of habitus as a socialized subjectivity that creates a priori barriers for access to higher education. Bourdieu and Passeron [4] argued that a proven inequality of access to higher education exists and that children of farmers have much slimmer chances of accessing a university than children of professionals.

Researchers in education have widely applied Bourdieu's theory to understand and explore the topic of access to higher education. A central conclusion of the recent research conducted through the lens of the theory of habitus is "the continuing influence of class on access to higher education" [7]. The rural students whose habitus is least congruent with the demands of entering a university either never access it [20] or experience more significant sacrifices to gain access compared to their counterparts from more privileged backgrounds [1].

Glaesser and Cooper [10] interviewed a group of high school students from various regional and family backgrounds in Germany and found that students who came from underprivileged rural backgrounds had much lower hopes for accessing higher education than their peers from middle class urban families. Glaesser and Cooper concluded that the respondents' habitus provided a sense of what was possible or impossible for them. Further, Dong [9] discovered in a case study of rural students studying at a Chinese university that when rural students access university despite the entrance challenges, they feel isolated and excluded. Habitus theory has recently received empirical support in the 
study of the relationship between underprivileged background and access to higher education.

The theory of habitus supports the notion that although access to higher education has increased overall for all categories of students, inequality of access among various groups still exists. The theory was appropriate for this study because of its focus on the influence of people's background on their place within the social world, including their chances of accessing higher education. The theory's underlining argument is that underprivileged groups of students including those of rural background have much more limited chances of accessing higher education than their counterparts from urban areas and privileged social background.

\section{Methodology}

The research questions of the study were as follows: (a) How do students from rural areas of Kyrgyzstan and Tajikistan describe their experiences gaining access to higher education and (b) What do students from rural areas in Kyrgyzstan and Tajikistan identify as sacrifices and opportunities related to pursuing higher education? The nature of the study was qualitative, which Knapp [13] described as interpretive research that addresses how things work from the perspective of the participants.

I chose a case study design due to the qualitative nature of the research questions and purpose of the study. A case study is an in-depth description and analysis of participants within a bounded system [16]. Phenomenology was also considered and rejected as a design for this study. A phenomenological design focuses on lived experience and often depicts intense emotional experiences such as love, fury, or deception [16]. To conduct a phenomenological study, prolonged engagement in the field is required from a researcher, who needs to continually return to the core of the experience and its central meaning [16].

Although access to higher education of each individual participant was important, a specific case of a group of IMU's students coming from the rural areas was critical to understanding the phenomenon. The focus of the study was on explanation, analysis, and finding commonalities in the experiences of the students who come from rural areas. Because the study focused on experiences and perceptions of a bounded group of people to gain an in-depth understanding of the experiences, the qualitative instrumental case study design was appropriate.

\subsection{Participants}

Participants for this study were 10 current IMU students out of the population pool of 60 who come from the rural areas of Kyrgyzstan and Tajikistan. The sampling procedure was purposeful criterion- based sampling. The sample included students who were over 18 years of age from a rural area. Research did not begin without a signed letter of cooperation for research from a designated IMU representative because IMU does not have an IRB. Once approved, I sent a confidential letter that explained the purpose of the study via institutional e-mail to 60 students who met the sampling criterion to solicit their participation in the study. Ten participants replied and confirmed via e-mail that they qualified for the study in terms of their age and rural status and that they agreed to participate. Following the agreement to participate, I scheduled interviews with each participant at a mutually agreed time. When confirming the eligibility, I invited participants to ask questions about the study and the interviewing process, but none of them posed any questions.

Ethical protection of the participants was a priority for this study. All potential participants who received the letter were informed of the voluntary nature of participation and protection of their personal information. They were also informed that any personal identifying information would be masked by the assigned participant numbers (i.e., Participant 1, Participant 2) and they would not be identified by their real names in the results. The ethical protection was applied beyond protecting confidentiality; the participants were treated with care and respect. An overview of the study and the rights of the participant was provided prior to each interview.

\subsection{Data collection and analysis}

The primary method of data collection was semistructured interviews with open-ended questions. All interviews were conducted one-on-one and in person in a quiet, sheltered student lounge area of IMU outside of class hours to ensure privacy. The interviews lasted no longer than 60 minutes. All interviews were recorded, transcribed, and analyzed using the elemental coding method with a combination of in vivo, or verbatim, and initial coding techniques. The codes were then grouped to identify the themes.

Meeting the credibility requirements was a priority of this research. I guaranteed the accuracy and credibility of this study through audio recording of the interviews, member checking, reflective journaling, and analyzing discrepant and negative cases.

\section{Results}

The analysis of data yielded four themes, which were as follows: (a) academic barriers, (b) information and communication barriers, (c) support, and (d) material and non-material sacrifices. The first three themes responded to the research question 
about how students from rural areas of Kyrgyzstan and Tajikistan describe their experiences accessing higher education. The fourth theme responded to the research question about what students from rural areas in Kyrgyzstan and Tajikistan identify as sacrifices related to pursuing higher education.

\subsection{Academic barriers}

The first dominant theme, academic barriers, is directly connected to the first research question about how students from rural Kyrgyzstan and Tajikistan describe their experience with gaining access to higher education. Although some participants pointed out that they went to the best high schools available in their villages or towns, all ten participants emphasized poor quality rural schooling as one of the most significant challenges of gaining access to higher education.

Rural schools do not retain teachers, and when teachers leave for better opportunities, schools often struggle to replace them. As Participant 8 observed, "The quality of teachers [in villages] is not so good because of their salary... there are of course, like, some qualified teachers, but as soon as they have, like, an opportunity they move [to] urban areas."

According to some participants, rural teachers also struggle to deliver modern curriculum, especially in the areas of languages and information technology. For example, Participant 6 revealed that they never learned reading rules of the English language in school and simply pronounced the words phonetically, which she only realized after she became a university student. Some participants felt that they were constantly neglected by their teachers because the goal of the schools was to concentrate on high-performing students who could represent the schools at various academic competitions.

Sometimes a syllabus for courses is not given to students, meaning they often do not know what they will study the next day (Participant 7). Participant 1 shared, "Even if you are smart, you can't, like, get good education or learn English language or other languages if you live in rural areas." When I asked her to explain why she thought this was so, Participant 1 exclaimed, "Because our teachers didn't teach us well!" Rural schools are lacking study materials such as textbooks (Participant 1; Participant 7; Participant 6) and basic computers (all participants). Even when schools have computers, Internet access is often not available in schools and, as a result, computers are not used by students.

A consensus among the participants was that urban schools were of higher quality, thus better equipping urban students for entering higher education. Nine out of ten participants had taken academic work outside of school to prepare themselves for the university entrance exams. Participants from bigger towns had an opportunity to participate in extra academic classes in their own towns but others had to travel various distances.

All participants I interviewed felt that the quality of schools in rural areas of Kyrgyzstan and Tajikistan was below the level required for an adequate preparation to enter higher education. The participants described low quality of rural schools in terms of (a) absence of teachers in certain subjects, (b) inability of teachers to deliver the curriculum, and (c) lack of study materials that ranged from inadequate number of textbooks in schools to lack of equipment.

Poor academic preparedness of rural high school graduates impedes access to higher education due to inability of rural students to pass entrance exams. The findings also revealed that gaining access to higher education for rural students in Tajikistan and Kyrgyzstan required attending classes outside their schools at extra cost to prepare for the university entrance examinations.

\subsection{Information and communication barriers}

The second major theme that emerged from the interviews was information and communication barriers that all ten participants experienced to various extents while gaining access to the university. Information and communication barriers ranged from lack of information about educational options available to the participants to inability to send their application forms because of lack of access to technology. Participants who lived closer to regional centers were less deprived of information and means of communication with universities compared to those who lived in extremely remote areas. In rural areas of Kyrgyzstan and Tajikistan, basic devices that are taken for granted in developed urban centers, such as smart phones or computers, are often rare.

The study participants were able to access higher education; however, they all admitted that their journey to become university students was a hassle when lack of information was combined with lack of means of communication. For example, Participant 6 said that she had to leave her village for about a week and live in a regional center to be able to fill out a university application form, gather all the documents required for submitting the university application, and submit the application electronically. Consequently, she had to miss school and "faced a lot of problems in school." But Participant 6 believes she had no other choice as there was no computer or Internet in her very remote village. Participant 6 exclaimed, "I did not use Internet before, maybe in the $11^{\text {th }}$ grade I started to use it!" (The educational system of Kyrgyzstan and Tajikistan consists of 11 grades).

Lack of information about existing universities and admission processes coupled with lack of 
communication assets such as Internet or even basic phones impede access to higher education for rural students in Kyrgyzstan and Tajikistan. The findings are consistent with Spoor's [18] conclusions that remoteness and rurality are a significant barrier for social inclusion of residents of developing countries including those of Central Asia.

\subsection{Support}

The third theme that emerged from the interviews was support. When describing their experiences with gaining access to higher education, nine out of ten participants felt positively about the institutional support that IMU offered them during the admission processes. All ten participants were also strongly supported by their families and communities while fulfilling their aspirations to become university students. The participants described institutional support's important role during their admission process in terms of providing both practical advice and inspirational community support, which helped build their self-confidence.

Although all participants acknowledged the importance of institutional support, they also discussed the importance of family and community support. Some applicants stated that "being from [a] remote area is just being surrounded with the community who were, like, trying to help each other, everybody cares about each other" (Participant 8). Being surrounded by a community that is helpful is inspiring for rural students (Participant 1).

Study participants appreciated institutional and family support and believed that support has been crucial for success in gaining access to higher education. Participant 3 mentioned that even though the IMU recruiter was "sick" of him, the recruiter was consistently patient and helpful. Study participants also reiterated that they would not have been able to gain admission to the university without the support of families and whole communities. These findings are consistent with earlier findings [8, 15] that although rurality posed many disadvantages for students seeking access to higher education, it also provided advantages in the form of stronger community support than urban areas provided.

\subsection{Material and nonmaterial sacrifices}

The last theme that emerged from the interviews was material and non-material sacrifices participants and their families made while participants pursued higher education. The theme is related to the second research question of the study, which was as follows: "What do students from rural areas in Kyrgyzstan and Tajikistan identify as sacrifices and opportunities related to pursuing higher education?" All participants shared that their families had to sacrifice financial resources to facilitate access to higher education for participants. Families were saving money for extracurricular academic courses and tutoring, application fees to higher education institutions, and tuition. To earn more money, participants' parents and even grandparents often took more work.

Material sacrifices went beyond saving money. Sometimes, families had to make a choice between higher education and other major milestones. For example, Participant 6 shared the following anecdote about a family sacrifice: "Actually, my sister... it was close to her wedding... and there was a choice, her wedding or my study, and my study came first." Participant 7 reported that her widowed mother never bought anything for herself and put all earnings of a grocery store cashier toward her four children. To fund extracurricular academic work, Participant 1's family had to sell a few sheep. Similarly, Participant 2's grandparents had to sell a cow. Both Participants 1 and 2 stated that farm animals are a significant asset for rural families in Kyrgyzstan, and to sacrifice this asset is never an easy decision.

Participants shared that a majority of rural families have vegetable and animal farms. Rurality in Kyrgyzstan and Tajikistan implies more household chores for students. The adults in the families of the participants often sacrificed their own leisure time to allow their children to study:

"[F]irst I need to tell [you] about their time, because as a girl ... in Kyrgyzstan, we have, like, responsibilities to do, for example, you need to take care of food, take care of the house or something like this. So, my mom was, like, taking care of this all and was sacrificing her time. She should have taken rest and go somewhere or go to courses, or ... meet with her friends, [but] she was, like, saying, "no, let's do like this, you will go to study and I will stay" [and work around the house], and she sacrificed her time." (Participant 6)

"I was just free from all the housework, actually. We have [our] own space in the field, own territory, and we have to irrigate it, and even though my grandfather is about 60 , he is doing it by himself." (Participant 8)

When asked about family sacrifices, Participant 3 simply stated with a heavy sigh, "Health." Participant 3 then stated that his parents are in their mid-forties but "are really getting a lot of issues with their health. Because they were working everywhere in order to get money for our education." His parents were migrant workers taking low paying jobs to survive and educate their two sons.

"My mom was cleaning houses five days per week. So, every day she had work to do on three floors. And every day she had issues with her back. And now because of her back she feels pain everywhere... I can say that I had a very happy childhood. Even though my parents were getting low 
salary. They were providing us with great childhood." (Participant 3)

The study participants expressed appreciation and gratitude to their parents and grandparents for often sacrificing basic needs to facilitate access to higher education. A majority of the participants mentioned that, once they earn their degrees and start working, they intend to support their parents and grandparents.

All ten participants pointed out that their families sacrificed material and non-material resources to help the participants become university students. The question of sacrifices produced some of the most emotional interview responses. The study participants believed that financial resources were important to accessing higher education, not only in terms of affordability of higher education itself but also in terms of paying for courses outside of high school to ensure an adequate academic preparation to pass university entrance exams. These findings are consistent with the earlier findings $[11,14]$ that rural students face additional financial burdens, compared to their urban counterparts, that often impede their access to higher education.

\section{Discussion}

As predicated by the theory of habitus, research results confirmed that all study participants experienced academic, information, and financial barriers while gaining access to higher education, which participants believed were predetermined by their rural origin. The predetermined nature of barriers to higher education for rural residents implies that, without external interventions, these barriers are difficult to overcome. Although Bourdieu's [2] theory of habitus as a predetermined disposition was used as a theoretical framework for this study, another aspect of Bourdieu's theory, the aspect of the field, was directly related to the research results and project recommendations. According to Bourdieu and Passeron [4], when access to higher education is limited by students' habitus, the field of education, or educational institutions, can facilitate the process of overcoming the constraints created by the habitus. Burke [7] interpreted Bourdieu and Passeron's concept of field to mean that access problems, deeply rooted in classed lines, could be resolved through the educational system. Therefore, institutional strategies and interventions can help students overcome barriers and enable access to higher education for rural students.

The institutions that exist in a person's habitus also exert influence on higher education access. Perna and Kurban [17] termed this phenomenon organizational habitus, explaining how institutional structures and resources could "facilitate or impede" students' access to higher education. Students who come from low-income families, rural areas, or from a low socioeconomic background rely on organizational habitus and its agents more than their high-income urban counterparts [17]. The results of this study revealed a need for institutional policies and practices that will facilitate the eradication of academic, information and communication, and financial barriers for rural students.

\section{Recommendations}

Based on the findings of the study, the following recommendations for practice could include (a) establishing partnerships with high schools, (b) developing outreach programs for rural parents, and (c) introducing inclusive admission practices for underrepresented student groups.

Partnerships between higher education institutions and high schools are an important instrument for creating college-going culture among high school students [6]. The results of this study revealed that academic underpreparedness was perceived by study participants to be a result of low-quality teaching in rural areas of Kyrgyzstan and Tajikistan. Improving the quality of teaching in rural areas could one of the sought outcomes of partnerships between higher education institutions and rural schools.

Developing parent outreach programs can help parents provide meaningful support to their high school students during the process of applying to higher education. Outreach programs are especially advisable for families of students who are underrepresented in higher education [17]. A parent outreach program could assist IMU in enrolling more students from rural areas of Kyrgyzstan and Tajikistan. Material sacrifices and financial aid emerged from this study as important components of the admissions process. Therefore, it is important that parent outreach programs focus on refining parents' knowledge of available mechanisms to pay for higher education in addition to the academic component of college readiness [17].

. To counteract inequalities of access, in addition to providing extra academic and process support to rural students, institutions of higher education could employ affirmative admissions practices [12]. The affirmative admissions practices could include (a) greater emphasis on non-cognitive characteristics of the applicants from rural areas compared to the applicants from urban areas and assigning extra admission points for rural students, and (b) including representatives from rural areas on admissions committees.

\section{Conclusion}

In this exploration of access to higher education for students from rural Kyrgyzstan and Tajikistan, I clearly demonstrated that, despite a global trend of 
increased participation in higher education overall, rural residents are still accessing higher education at much lower rates than urban residents. Evidence of social exclusion among rural residents worldwide, including in Kyrgyzstan and Tajikistan, is abundant. The rural-urban divide creates complex problems impacted by family backgrounds, academic preparedness, financial status, and rurality itself.

The scope of the study was limited to rural students' perceptions of gaining access to higher education. Further research could explore gender as a factor in gaining access to higher education in Kyrgyzstan and Tajikistan. Another potential area for further research is to explore access to higher education from the perspective of rural teachers and administrators. By investigating these topics, researchers and practitioners can gain a broader and deeper understanding of the barriers to higher education for rural students and propose more solutions to combat these barriers

\section{References}

[1] M. Arnot and A. Naveed, "Educational Outcomes Across the Generational and Gender Divide: The Rural Family Habitus of Pakistani Families Living in Poverty", Gender and Education, 26(5), 2014, 505- pp.523. doi:10.1080/09540253.2014.949635.

[2] P. Bourdieu, Outline of a Theory of Practice (R. Nice, Trans.), Cambridge University Press, Cambridge, England, 1977.

[3] P. Bourdieu, "The Social Space and the Genesis of Groups", Theory and Society, 4(6), 1985, pp.723-744.

[4] P. Bourdieu and J-C. Passeron, Reproduction in Education, Society, and Practice, (R. Nice, Trans.), SA, London, England, 1990.

[5] P. Bourdieu and LJ.D. Wacquant, An Invitation to Reflexive Sociology, The Chicago University Press, Chicago, IL, 1992.

[6] C.G Brown and J.A. Scott, "Who are We Choosing for School Leaders? A Review of University Admission Practices", International Journal of Educational Leadership Preparation, 9(2), 2014, pp.1-9.

[7] C. Burke, "Capitals and Habitus. A Bourdieusian Framework for Understanding Transitions into Higher Education and Student Experiences" in A. MountfordZindars and N. Harrison (Eds.), Access to Higher Education. Theoretical Perspectives and Contemporary Challenges, Routledge, London, UK, 2017, pp.61-79.

[8] S.Byun, J.L. Meece, and M.J. Irvin, "Rural-Nonrural Disparities in Postsecondary Educational Attainment Revisited", American Education Research Journal, 49, 2012, pp.412-437. doi:10.3102/0002831211416344

[9] J. Dong, "A Case Study of "Habitus" and "Field": The Chinese Rural Students on the University Campus",
Problems of Education in the $21^{\text {st }}$ Century, 40, 2012, pp.45-65.

[10] J. Glaesser and B. Cooper, "Using Rational Action Theory and Bourdieu's Habitus Theory Together to Account for Educational Decision-Making in England and Germany", Sociology, 48(3), 2014, pp.463-481. doi: $10.1177 / 0038038513490352$

[11] A.J. Jaeger, S.B. Dunston, and K.G. Dixon, "College Student Access: How Articulation Agreements Support Rural Students", Peabody Journal of Education, 90(5), 2015, pp.615-635. doi:10.1080/0161956X.2015.1087771

[12] Q. Jia and D.P. Ericson, "Equity and Access to Higher Education in China: Lessons from Hunan Province for University Admissions Policy", International Journal of Educational Development, 52, 2017, pp.97-110. doi:10.1016/j.ijedudev.2016.10.011

[13] M.S. Knapp, “The Practice of Designing Qualitative Research on Educational Leadership: Notes for Emerging Scholars and Practitioner-Scholars", Research on Leadership Education, 2016, pp.1-25. doi:10.1177/1942775116647365

[14] M. Li, and R. Yang, "Interrogating Institutionalized Establishments: Urban-Rural Inequalities in China's Higher Education", Asia Pacific Education Review, 14, 2013, pp.315-323. doi: 10.1007/s12564-013-9262-0

[15] D.R. Means, A.B. Clayton, J.G. Conzelmann, P. Baynes, and P.D. Umbach, "Bounded Aspirations: Rural, African American High School Students and College Access", The Review of Higher Education, 39(4), 2016, pp.543-569. doi: 10.1007/s12564-013-9262-0

[16] S.B. Merriam, Qualitative Research: A guide to Design and Implementation, Jossey-Bass, San-Francisco, CA, 2009.

[17] L.W. Perna and E.R.Kurban, "Improving College Access and Choice" in L.W. Perna and A.P. Jones (Eds.), The state of college access and completion: Improving college success for students from underrepresented groups, Routledge, New York, NY, 2013, pp.10-33.

[18] M. Spoor, "Multidimensional Social Exclusion and the "Rural-Urban Divide" in Eastern Europe and Central Asia", Sociologica Ruralis [Rural Sociology], 53(2), 2013, pp.139-157.

doi: $10.1111 /$ soru. 12008

[19] United Nations, Sustainable mountain development, 2014. Retrieved from http://www.mountainpartnership.org/fileadmin/user_uploa d/mountain_partnership/docs/A_RES_68_217.pdf

[20] J. Watson, "Widening Participation in Higher Education: Capital that Counts" in M. Grenfell and F. Lebaron (Eds.), Bourdieu and Data Analysis. Methodological Principles and Practice, Peter Lang AG, Bern, Switzerland, 2014, pp.97-116. 